\title{
Promoting learning with understanding: Introducing languaging exercises in calculus course for engineering students at the university level
}

\author{
Helen Alfaro ${ }^{1,2}$ and Jorma Joutsenlahti ${ }^{1}$ \\ ${ }^{1}$ Tampere University, Faculty of Education and Culture, Finland \\ ${ }^{2}$ University of Costa Rica, School of Mathematics, Department of Mathematics Education, Costa Rica
}

The study of mathematics at the university level requires logical thinking and strong mathematical skills. Contemporary first-year students are not prepared for these demands and end up failing their courses. This study aims to present an instrument for enhancing mathematics teaching and promoting learning with understanding in higher education by a combination of symbolic, natural, and pictorial languages in different tasks. We analyze the 17 solutions of four languaging exercises administered in a basic calculus course for engineering students at the University of Costa Rica. The results suggest that these exercises promote the acquisition of skills necessary to be mathematically proficient and are a useful tool for revealing students' mathematical thinking and misconceptions.

Keywords: languaging, university mathematics teaching, mathematical proficiency derivatives

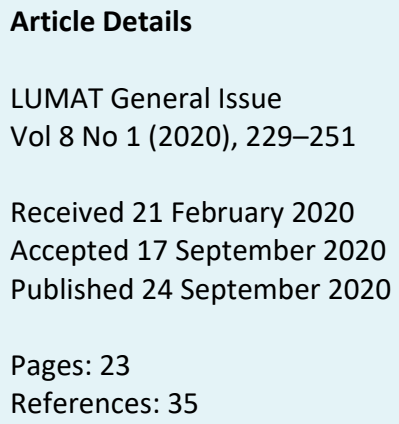
LUMAT.8.1.1412

\section{Introduction}

In the last years, research in university mathematics education has increased substantially (Biza et al., 2016; Goodchild \& Rønning, 2014), and the transition from high school mathematics to university mathematics has been intensely discussed (Winsløw et al., 2018; Varsavsky, 2010). There is a general concern about first-year students' unpreparedness to face university level mathematics. A significant portion of students enrolled in non-mathematics majors experience the consequences of this knowledge gap, which are seen in the alarming rates of failure and dropout presented in the mathematics courses taken (Biza et al., 2016; Fox et al., 2017).

Several researchers (e.g., Artigue, 1995; Kilpatrick et al., 2001; Winsløw et al., 2018) point out that students enter the university without strong mathematics knowledge. This problem was already identified in 1972, as presented by Hoyles, Newman, and Noss (2001) in this excerpt that points out that:

"[students] do not understand the mathematical ideas which university teachers consider basic to their subject; they are not skillful in the manipulative processes of even elementary mathematics; they cannot grasp new ideas quickly or at all; ... and, particularly, they have no sense of purpose that is, they 
do not seem to realize that in order to study mathematics intensively they must work hard on their own trying to sort out ideas new and old, trying to solve test problems, and so on." (Thwaites, 1972, as cited in Hoyles et al., 2001, p.831)

Contemporary students continue to present the same difficulties. They have deficiencies in problem-solving skills, conceptual understanding, and the thinking and reasoning skills needed for the university level (Kempen \& Biehler, 2014; Er, 2018; Gruenwald et al., 2004; Luk, 2005). Although they are successful in tasks of mechanical calculation, the practical and theoretical meaning of the lessons' contents is not clear to them. It is evident that there is a knowledge gap between high school and university mathematics that influences the students' performance.

Biza et al. (2016) and Hong et al. (2009) associate students' low performance in the first courses of university mathematics with changes in teaching styles, required study and learning strategies, and the nature of the mathematics that is taught.

This knowledge and the cultural gaps should be addressed by institutions of higher education by promoting conceptual understanding (Engelbrecht \& Harding, 2015). These initiatives must convey the connections between concepts (Nardi, 1996), the abstract nature of mathematical notions, and the complexity of mathematical thinking (Biza et al., 2016).

Some universities have taken measures to fill in the gaps in first-year university students' knowledge of mathematics, such as peer work, bridging courses, and mathematical support centers (Mustoe \& Lawson, 2002). Initiatives that work on improving conceptual understanding have been introduced in some engineering courses at the University of Tampere. In this institution, they have used languaging exercises as a tool for improving students' understanding of concepts (e.g., Rundgrén et al., 2016). This strategy showed favorable results not only for improving students' understanding but for promoting learning and improving the students' grades.

As in other countries, in Costa Rica, the knowledge gap between high school and university mathematics is a significant problem. This situation led the University of Costa Rica to introduce, in 2015, a mandatory precalculus course for students in nonmathematics majors with severe mathematical deficiencies. However, the course has had a pass rate of only 40\% (Blanco, 2019). A significant problem with the math courses for engineering students has been that the teaching methods and objectives of the course are not focused on improving students' conceptual understanding but on reinforcing the mechanical solution of equations such as limits, derivatives, and integrals. According to the course syllabus, the approach is not formal, focused on proofs, but is instead focused on applications and practicing calculation techniques 
(University of Costa Rica, 2019). Classes consist mainly of lectures in which the teacher explains the concepts and solves examples. The role of the student is more of a receiver and less of a participant.

The present research aims to improve university mathematics teaching at the University of Costa Rica through the use of languaging exercises in classes. The exercises integrate the use of natural, symbolic, and pictorial language and aim to improve students' mathematical understanding, mathematical communication, and justification skills, as well as help students to be aware of their mathematical thinking. This proposal intends to move from the traditional teaching method commonly used in the university's calculus courses towards an alternative in which students participate in their learning process. In the same way, it aligns with the need for initiatives that deal with the difficulties in the transition from high school to university mathematics, addressing the abstract character of the mathematical concepts and the complexity of the mathematical thinking (Biza et al., 2016).

\section{Theoretical framework}

\subsection{Mathematical proficiency}

In the field of mathematical education, how mathematics learning is conceived of has changed over the years. According to Boesen (2014), these changes have focused on highlighting that knowing mathematics implies more than knowing how to perform procedures; it is about doing mathematics from a broader perspective. The model of mathematical proficiency (Kilpatrick et al., 2001) aligns with this perspective and provides an outline for the competencies needed to achieve mathematical understanding.

Kilpatrick et al. (2001) consider five main competencies that are necessary for learning mathematics: conceptual understanding, procedural fluency, adaptive reasoning, strategic competence, and productive disposition. This model intends for students to learn with understanding, since "learning with understanding is more powerful than simply memorizing because the organization improves retention, promotes fluency and facilitates learning related material" (Kilpatrick et al., 2001, p. 118). For the authors, deep understanding requires the connection of individual pieces of knowledge. They emphasize that their five main competencies are intertwined; in other words, each depends on the others to fully develop and be useful for solving mathematical problems. Consequently, each competency should receive the same 
importance in the educational context. Table 1 shows the skills of each competence that are important at the university level, and for the interests of this research.

Table 1. Specific skills for each competence

\begin{tabular}{l|l}
\hline & - Understand why a mathematical idea is important \\
& - Understand when and where an idea is useful \\
Conceptual & - Understand, identify, and verbalize connections between concepts \\
Understanding & - Remember and reconstruct methods \\
& - Monitor students' work \\
& - Expresent mathematical situations in different ways \\
& - Understand and use mathematical concepts in various contexts properly \\
\hline & - Know when and how to use procedures appropriately, \\
Procedural & flexibly, accurately, and efficiently \\
Fluency & - Performing mental methods \\
\hline & - Mechanical counting, solving procedures, simplifying \\
\hline Strategic & - Know a variety of solution strategies \\
Competence & - Select strategies for solving problems \\
& - Formulate problems \\
\hline Adaptive & - Know different representations of problems and select the most useful \\
Reasoning & - Flexibility of approach, solve novel situations \\
\hline Productive & - Knowledge of how to justify conclusions \\
Disposition & - Give informal explanations and justifications \\
\hline
\end{tabular}

Source: Based on Kilpatrick et al. (2001).

This model has been used before in research related to improving students' understanding of mathematics at the university level (e.g., Silius et al., 2011; Joutsenlahti et al., 2016). Working on the development of these competencies could increase the chances of learning with understanding, which would be beneficial for students in terms of advancing in their studies successfully.

\subsection{Languaging for expressing mathematical thinking}

Language has been proved to play a significant role in teaching and learning mathematics. From a social-semiotic point of view, it is not only a powerful tool for communication and representation but also for thinking and meaning-making (Schleppegrell, 2010). According to Prediger and Wessel (2013), the construction of new mathematical concepts requires the acquisition of new means for expressing 
them. It is in this sense that Joutsenlahti and Kulju (2017) present languaging as a multimodal approach for developing students' meaning-making processes in mathematics.

Languaging is defined as the student's expression of their mathematical thinking across different modes. Seen in terms of languaging, mathematical thinking is "an information process monitored by one's metacognition” (Joutsenlahti \& Kulju, 2017, p. 3). The expression of the students' mathematical thinking is observed through oral or written languaging exercises, involving three languages: mathematical symbolic (SL), natural (NL), and pictorial (PL) (see Figure 1). The combination of different languages promotes the construction of connections and aims to support the student's meaning-making process (Joutsenlahti et al., 2016), since they access three different meaning potentials (i.e., SL, NL, and PL) to construct mathematical reality. Each language shows specific properties and connotations of the mathematical concepts (O'Halloran, 2015).

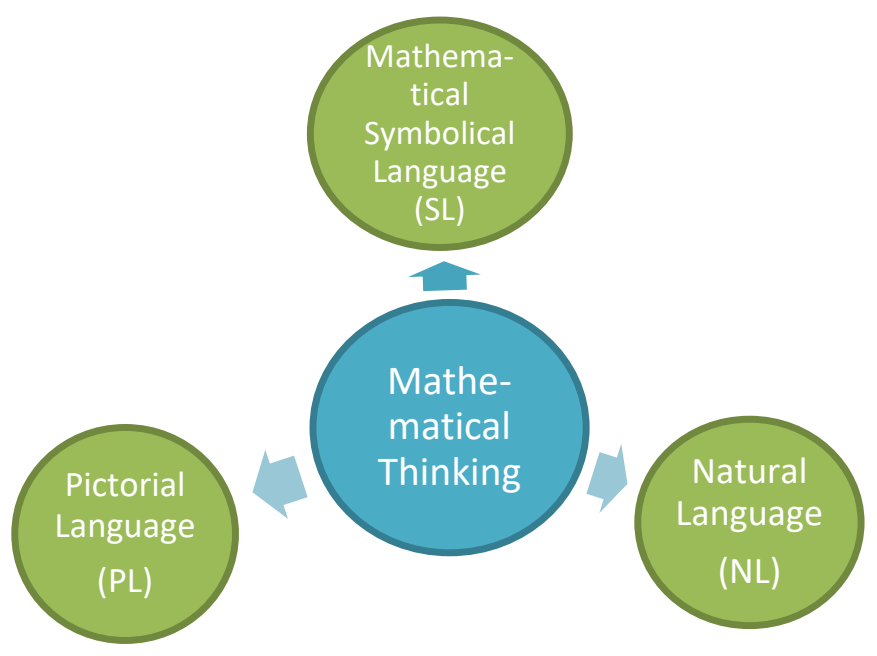

Figure 1. Languages used for expressing mathematical thinking. Adapted from Joutsenlahti \& Kulju (2017).

Moreover, the literature suggests that, through writing, students try to express their thinking process clearly and concretely so that readers can understand (Morgan, 2002). Students must sort out their thoughts and review and clarify their mental processes to explain them to others orally or in writing. This practice will improve their understanding of mathematical concepts (Kline \& Ishii, 2008; Silius et al., 2011). Having the answers written and explained in the students' own words helps teachers 
to follow the mathematical thinking of students, and it is also useful for students to understand the solution processes afterward (Morgan, 2002; Silius et al., 2011).

At this point, it would be valuable to clarify the link between languaging theory and the mathematical-proficiency model. On the one hand, the use of NL and students' own words relate to adaptive-reasoning skills when giving explanations and justifications, as well as to conceptual understanding when verbalizing connections between concepts. On the other hand, SL and the PL are present in strategic competency when knowing and selecting different solution strategies, in procedural fluency when solving procedures accurately and efficiently, and in conceptual understanding when representing mathematical situations in different ways.

In this article, we use languaging theory to address the study of derivatives in a calculus course. Derivatives are essential content for non-mathematics majors in any basic calculus course because of their many applications in fields such as economics, engineering, and biology. Derivatives can be represented in different ways according to the interpretation given to them. For example, it can be understood geometrically with pictorial representation as the slope of the line tangent to a curve at a given point, an interpretation that will be strictly linked to the algebraic-symbolic representation of the equation of a line (Kaplan et al., 2015). A complete understanding of derivatives concept requires understanding each of its interpretations and representations, including the connections between them.

Considering the multi-representational characteristics of the concept of derivatives, languaging theory offers an appropriate way to approach its study.

\subsection{The study of derivatives: The Costa Rican context}

In Costa Rica, the topic of derivatives is not included in the mathematics curriculum in high school, although it might be studied in some private high schools, scientific high schools, or special optional programs in advanced mathematics that public universities offer in secondary school. Therefore, when students get to university and take their first mathematics courses, they have no or only a little knowledge about derivatives and their applications. At the University of Costa Rica, this topic is covered for engineering majors in the Calculus I course, after the study of limits. The course contents include (a) the definition of derivatives as a limit; (b) differentiation rules, relationship between continuity and differentiability; (c) derivatives as the slope of tangent lines; (d) derivatives as rates of change; (e) optimization problems; (f) minimum and maximum; and (g) graphing. However, all these topics are studied from 
a procedural point of view; that is, the focus is on learning and practicing calculation techniques (Universidad de Costa Rica, 2019). Some content, such as optimization problems, requires problem-solving skills, but the emphasis is still on the calculations. Consequently, students are trained in procedural fluency but do not develop the rest of the mathematical-proficiency model skills.

Considering the evidence presented above, in this study, we aim to answer the following research questions:

1. How are mathematical-proficiency features shown in answers to the languaging exercises?

2. How do answers to the languaging exercises reveal students' mathematical thinking about derivatives?

\section{Methodology}

\subsection{Data collection and analysis}

The exercises analyzed in this article are part of the instruments used in one study about students' perspectives on the use of languaging exercises developed in the University of Costa Rica in 2017 (Alfaro, 2018). Initially, 17 languaging exercises covering derivatives were designed and applied in a course for first-year engineering majors in Calculus I at the University of Costa Rica. The exercises were reviewed by the collaborating teachers' previous implementations to ensure consistency of language and context. For this study, we chose four languaging exercises that exemplify the usefulness of this tool in developing mathematical-proficiency skills and reveal the students' mathematical thinking. We analyzed the solutions of 17 engineering majors from the University of Costa Rica. The participants voluntarily agreed to participate and were informed that their performance in the exercises would not affect their course grade and that the data would be treated confidentially.

The collaborating teachers received information about the languaging theory and the desired objective of the exercises. However, they were free to decide when to implement the exercises as they progressed through the program. In the same way, they decided at what point in the class to use the exercises, for example, to introduce the topic, as an example, or as homework. Students did not receive any special language training before solving the exercises other than references to the various representations that teachers used when giving lectures. Therefore, the use of 
languaging exercises in this study intents to introduce the students to a way of solving exercises where they have to make more connections. They are a methodological tool more than a methodology itself.

From the languaging exercises, we received answers in NL, PL, and SL that led us to a direct qualitative content analysis (Hsieh \& Shannon, 2005) based on the mathematical-proficiency model, using the concepts in Table 1 as a guide and with the specific aspects of each strand as described by Kilpatrick et al. (2001). This analysis addresses the first research question. The productive-disposition strand was not considered, as it was difficult to observe through students' written solutions. In order to answer the second research question, we performed a conventional content analysis considering the mathematical contents included in the course syllabus about derivatives.

\subsection{Description of the exercises}

The following is a description of Languaging Exercises 3, 14, 16, and 17: Exercise 3, shown in Figure 2, studies three cases in which a function is not differentiable. Each case is represented in the table using a different language. The students' task is to fill in the empty boxes with the representations in the missing languages. This exercise includes knowledge of the definition of derivatives (geometric, analytical), conditions of derivability and continuity, understanding and calculation of limits, and basic notions of graphing functions. The purpose of the exercise is to observe whether students have clarity about the concepts and rules involved so that they can use them with any of the representations given and express them in different ways. This exercise focuses on conceptual understanding and adaptive reasoning, as described in Table 1. Additionally, it supports the use of the three languages suggested by languaging theory. 
What are the possible cases in which a function is not derivable?

Give examples of each of them using the three types of languages.

\begin{tabular}{|l|l|l|l|}
\hline & $\begin{array}{l}\text { Mathematical symbolic } \\
\text { language: numbers, } \\
\text { symbols. }\end{array}$ & $\begin{array}{l}\text { Natural language: } \\
\text { written words. }\end{array}$ & $\begin{array}{l}\text { Pictorial language: } \\
\text { drawings, graphs, etc. }\end{array}$ \\
\hline I & $\begin{array}{l}\text { At points where the } \\
\text { curve presents peaks } \\
\text { since the lateral } \\
\text { derivatives would be } \\
\text { different. }\end{array}$ & \\
\hline II & $f(x)=\sqrt[3]{x}$, in $x=0$ & & \\
\hline III & & & \\
\hline
\end{tabular}

Figure 2. Languaging Exercise 3, from Alfaro (2018).

In Exercise 14, the analytic characteristics of a function are given using mathematical symbolic language (see Figure 3). The information involves intersections with the axes, maximum and minimum points, intervals of monotony and concavity, and details about the behavior of the function in the infinities. The students' task is to explain, in their own words, the graphical implication of each given statement and make a sketch of a graph that meets the given conditions. This exercise is similar to the one used by Baker et al. (2000) in their study, "A calculus graphing schema." As the authors point out, this is a non-routine exercise about graphing, which aims to evaluate if the students can interpret the given characteristics by providing accurate explanations and visualizations of the graphical implications of the features. This exercise promotes adaptive-reasoning skills connected to the use of NL when asking for explanations and justifications and besides it supports strategic competence (see Table 1). 


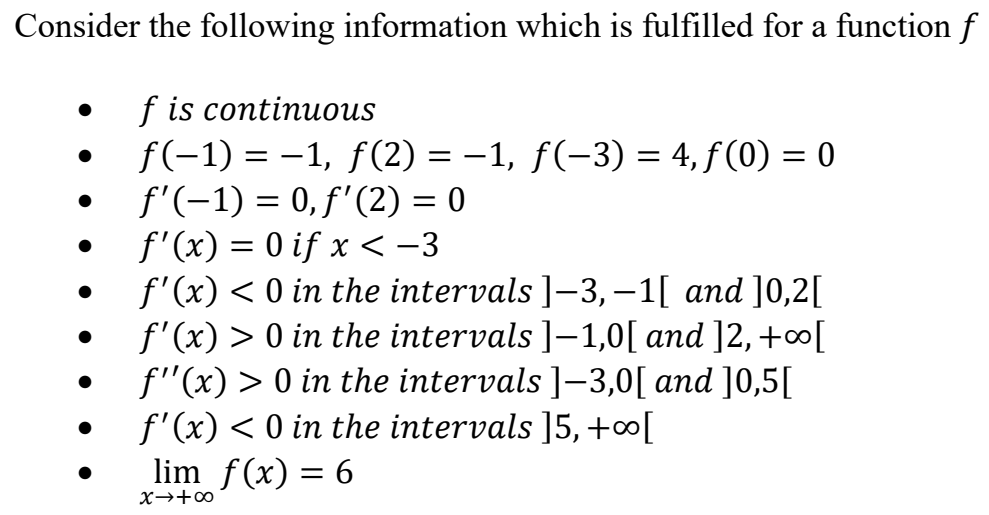

Explain in your own words the graphic implication of each of the above points. Then make an outline of the chart that meets the conditions.

Figure 3. Languaging Exercise 14, from Alfaro (2018).

Exercise 16 is an optimization problem in which students must find the measures that minimize the amount of material needed to build a cylinder, that is, its area, knowing its volume. Students are asked to assume that they have to explain how to solve the problem to one of their classmates and write that explanation in their own words, justifying the statements used and including the symbolic or pictorial elements they consider necessary. However, they do not need to solve the problem, that is, to perform the calculations. This exercise aims to identify if students understand how to solve this type of problem in a way that they can explain to others. While writing, students must revise the mental process they used for solving the problem. In this way, they become aware of the mathematical ideas, the connection between concepts and the strategies involved in the resolution of the optimization problems. In other words, it stimulates adaptive-reasoning skills and the use of NL together with the use of conceptual understanding (see Table 1).

Finally, Exercise 17 concerns the chain rule for deriving composite functions. The exercise shows a composite function and three attempts at solutions by three solvers. Two attempts show the steps of the solution in symbolic language, and the other shows a calculator's result. Students have to decide who got the right answer, determine the errors in the wrong answers, and present the correct solution. The objective of this exercise is to apply students' knowledge of the basic derivation rules, as well as the chain rule for composite functions, to identify the correct answer. The exercise is designed so that the correct answer is the calculators. Therefore, the students must construct the solution for the derivatives. The two incorrect solutions present errors that students frequently commit in this type of exercise, with the intention that, by identifying errors in the work of others, they will not commit them 
in the future. The skills from Table 1 promoted in this exercise are procedural fluency, conceptual understanding, and adaptive reasoning.

\begin{tabular}{|c|c|}
\hline \multicolumn{2}{|c|}{ We had $h(x)=g(f(x)), f(x)=e^{x}$ and $g(x)=2 x^{2}+1$. Daniel and Josué derivate $h^{\prime}(x)$ as follows } \\
\hline Daniel's answer & Josué's answer \\
\hline $\begin{array}{l}f(x)=e^{x} \\
g^{\prime}(x)=4 x \\
\text { so } h^{\prime}(x)=g^{\prime}(f(x))=4 e^{x}\end{array}$ & $\begin{array}{l}h(x)=g(f(x))=2\left(e^{x}\right)^{2}+1=2 e^{x^{2}}+1 \\
h^{\prime}(x)=2 e^{x^{2}} \cdot(2 x) \\
\text { so } h^{\prime}(x)=4 x e^{x^{2}}\end{array}$ \\
\hline \multicolumn{2}{|c|}{$\begin{array}{l}\text { María got the answer } 4 e^{2 x} \text { in the calculator. Who had the right answer? Find the errors in the wrong } \\
\text { answers and present the correct solution. } \\
\text { Source: Finnish Board of Matriculation Examination, Finland, Spring, } 2017 \text {. }\end{array}$} \\
\hline
\end{tabular}

Figure 4. Languaging Exercise 17.

\section{Results}

\subsection{Evidence of mathematical-proficiency strands in students' answers}

By means the model of mathematical proficiency, it was possible to identify various characteristics that relate to the strands in the students' answers: conceptual understanding, procedural fluency, adaptive reasoning, and strategic competence.

Conceptual understanding

Examples of specific skills of conceptual understanding were present in the students' answers. The dominant skill was the one that makes connections between concepts. This makes sense because the study of derivatives requires students to understand and be able to apply definitions and prior concepts, such as limits and continuity. Students must be able to understand the relationship between those concepts and derivatives. The connections were shown when the students related the symbolic form of a function with its respective graphic representation (Table 2A) by using previous knowledge to make conclusions (Table 2B) and when justifying the choice of strategies (Table 2C). 
Table 2. Connections between concepts in students' answers

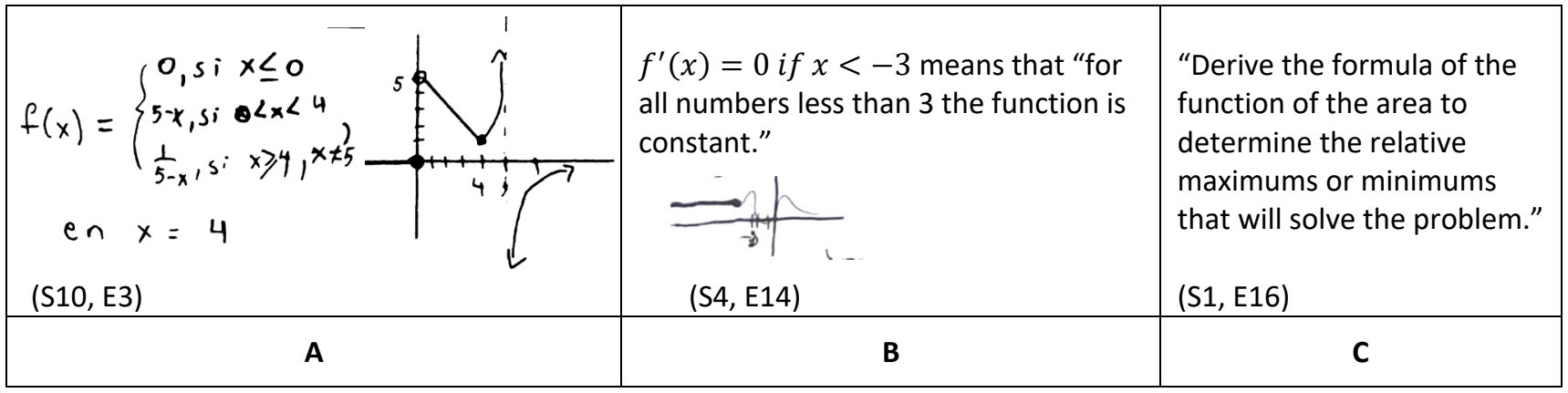

The students also proved to be able to represent mathematical situations in different ways, as seen in Exercise 3's answers, when they used the three languages for representing each case (Table $3 \mathrm{~A}$ ). The competences of understanding why a mathematical idea is important, and when and where to use it, are also shown. For instance, in Table $3 \mathrm{~B}$, the student had to recognize that the idea of the relative maximum and minimum gave him more useful information than the fact that the derivative was zero at those points. Likewise, in Table $3 \mathrm{C}$, the student explains why he decided to derivate the area, considering the given problem.

Table 3. Using different representations and understanding why and when mathematical ideas are useful.

\begin{tabular}{|c|c|c|c|c|}
\hline $\begin{array}{l}f(a) \neq \lim _{x \rightarrow a} f x x \\
\nexists \lim _{x \rightarrow a} f x\end{array}$ & $\begin{array}{l}\text { En puribos donde } \\
\text { hay discontinuidad } \\
\text { inevituble o no } \\
\text { existe un limite } \\
\text { general }\end{array}$ & \multirow[t]{2}{*}{$\begin{array}{c}\text { "At points } \\
\text { where there is } \\
\text { inevitable } \\
\text { discontinuity or } \\
\text { there is no } \\
\text { general limit." } \\
\text { (S4, E3) }\end{array}$} & \multirow[t]{2}{*}{$\begin{array}{l}\text { "The points } x=-1 \text { and } x=2 \text { are } \\
\text { critical, that is, the graph } \\
\text { changes monotony (the slope is } \\
\text { zero), it is a peak (a relative } \\
\text { max or min)." (S4, E14) }\end{array}$} & \multirow[t]{2}{*}{$\begin{array}{l}\text { "It is necessary to minimize the area } \\
\text { of the cylinder, which would be } \\
\text { equivalent to the amount of } \\
\text { material needed. This area is given } \\
\text { by } A=2 \pi r^{2}+2 \pi r h . "(\mathrm{~S} 10, \mathrm{E} 16)\end{array}$} \\
\hline & & & & \\
\hline \multicolumn{3}{|c|}{ A } & B & C \\
\hline
\end{tabular}

The ability to monitor their work and the ability to know when and how a procedure is correct are closely related. Students expressed how they used tools such as the sign chart to review their work: "A sign chart of the first derivative is made to see which critical number is the minimum" ( $\left.\mathrm{S}_{15}, \mathrm{E} 16\right)$. The chart was used in Exercises 14 and 16. Moreover, the solutions also showed that the students were able to identify and name the misapplied rules in Exercises 17: "In the case of Daniel, the 
error is that he derived a composition of functions without using the chain rule" (S10, E17). They were also able to correct those errors, as shown in Table 4.

Table 4. Knowing when a procedure is correct in a student's answer

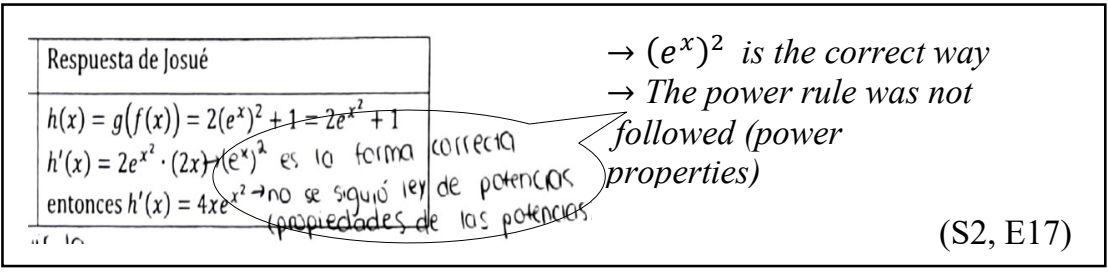

\section{Procedural fluency}

Procedural fluency is perhaps the most-practiced skill in mathematics classes. Many exercises, for example, those concerning limits and derivatives, consist of doing calculations and procedures. However, in the languaging exercises presented in this article, there was no need to repeatedly perform calculations or procedures. Therefore, the procedural fluency ability was reflected in the students' responses as calculations supporting the explanations and solutions (Table 5A) or in their evaluations of procedures developed by others and in showing the correct way to perform a procedure (Table $5 \mathrm{~B}$ ).

Table 5. Procedural fluency in students' answers

\begin{tabular}{|c|c|c|}
\hline $\begin{array}{l}A=\frac{2 \pi r^{3}+3}{r} \\
A^{\prime}(r)=\frac{\left.\left(6 \pi r^{2}\right) r-12 \pi r^{3}+3\right)}{r^{2}} \\
A^{\prime}(r)=\frac{6 \pi r^{3}-2 \pi r^{3}-3}{r^{2}} \\
(S 14, E 16)\end{array}$ & $\begin{array}{l}\text { "5) substitute the data of the } \\
\text { auxiliary [equation] and } \\
\text { derive the equation 6) obtain } \\
\text { the critical numbers and } \\
\text { confirm with the sing table." }\end{array}$ & $\begin{array}{l}\text { Sol correcta } \\
h(x)=g\left(f(x)=2\left(e^{x}\right)^{2}+1=2 e^{2 x}+1\right. \\
h^{\prime}(x)=2 e^{2 x} \cdot 2=4 e^{2 x} \\
(S 10, E 17)\end{array}$ \\
\hline & $\mathbf{A}$ & B \\
\hline
\end{tabular}

\section{Strategic competence}

Strategic competence was visible when students used strategies to prove that a point was a maximum or minimum using the first derivative test (Table 6A) or the concavity test ( Table 6B). This shows that they know multiple solution strategies and can select 
the best one or the one they feel most confident using; it means they are flexible about which approach to follow

Table 6. Examples of different solution strategies in the students' answers

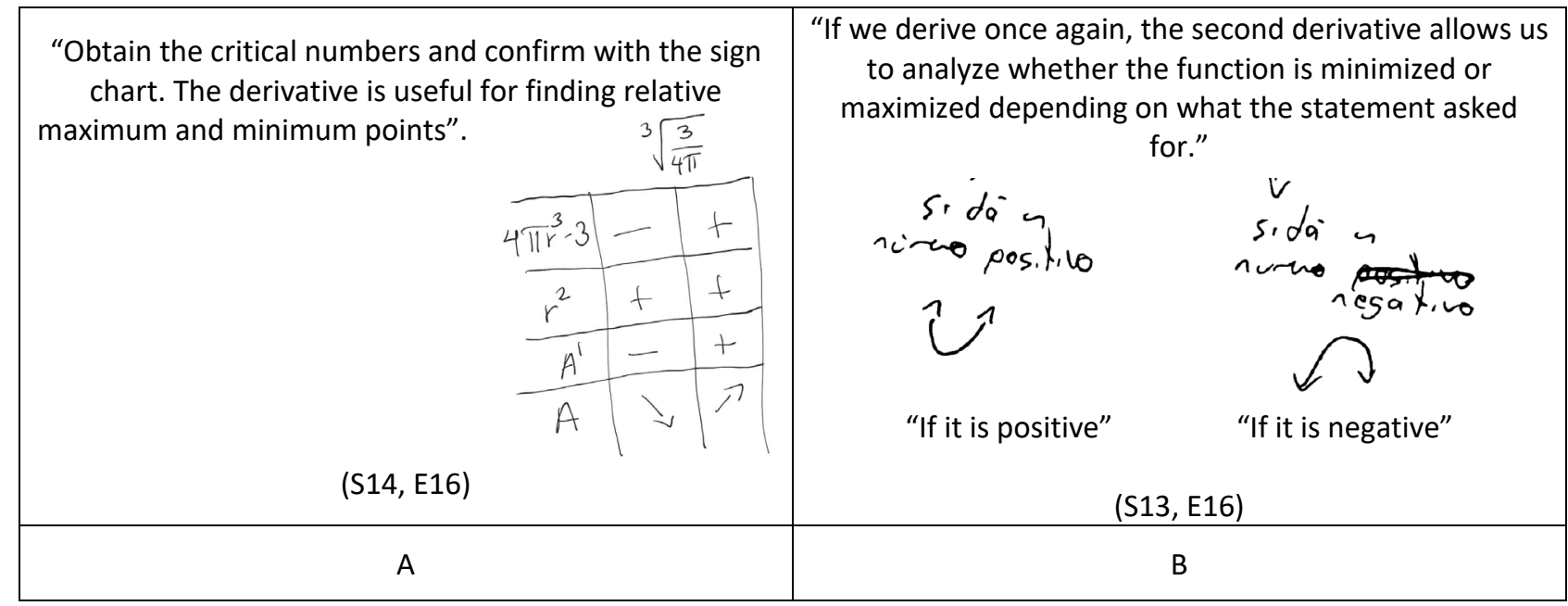

On a questionnaire given to the students (see Alfaro, 2018 for more details), they said that they were not used to providing explanations and justifications, meaning that those tasks were novel situations for them. Still, they were able to accomplish them, as shown in Table $3 \mathrm{C}$ and Table 6B.

\section{Adaptive reasoning}

Adaptive reasoning was exemplified in the ability to give informal explanations or justifications. The students provided explanations for the cases in which the function was not differentiable (Table $7 \mathrm{~A}$ ) when they interpreted the characteristics of a function ( Table $7 \mathrm{~B}$ ), and in processes, they used to solve the optimization problem ( Table $7 \mathrm{C}$ ). In addition to explaining, the students resorted to theory, using definitions and rules to add validity to their claims ( Table 7D). 
Table 7. Adaptive reasoning skills in students' answers

\begin{tabular}{|c|c|}
\hline$A$ & $\begin{array}{l}\text { "In the points where the derivative tends to }+\infty \text { since this would mean a perpendicular tangent } \\
\text { line, which does not exist." } \\
\text { (S10, Exercise } 3 \text { ) }\end{array}$ \\
\hline B & $\begin{array}{l}\text { - "It does not have vertical asymptotes" (S4) } \\
\text { - "The graph does not have gaps or peaks; it is a continuous function" (S1) } \\
\text { - "f is continuous if it has no gaps in its graph and there are no numbers that do } \\
\text { not have an image" (S16) } \\
\text { - "Any value that is used will serve to find values" (S13) } \\
\text { - "Differentiable function" (S3) } \\
\text { (E14) }\end{array}$ \\
\hline C & $\begin{array}{l}\text { "Understand that when talking about cylinder dimensions we relate it to the area of this" } \\
(\mathrm{S} 12, \mathrm{E} 14)\end{array}$ \\
\hline D & $\begin{array}{l}\text { "Maria, Daniel failed to derive } f(x) \text { and substitute it in } g{ }^{\prime}(x) \text {, on the other hand, Josué lacked to } \\
\text { resolve the property of the exponents, when power is raised to another power the exponents } \\
\text { multiply" } \\
\text { (S13, Exercise 17) }\end{array}$ \\
\hline
\end{tabular}

In the previous sections, the students' answers to the languaging exercises reveal some of the mathematical-proficiency features described by Kilpatrick et al. (2001). By using skills from the different strands in a variety of tasks, students improve their performance in competencies essential to successful mathematical learning.

\subsection{Evidence of students' mathematical thinking about derivatives}

To analyze the students' mathematical thinking when solving the exercises, we considered the derivative-related content in the curriculum for Calculus I at the University of Costa Rica. We identify the knowledge about derivatives that students understood and the misconceptions they had about some mathematical concepts.

Students' knowledge about derivatives

There were mathematical concepts that the students understood and explained correctly. For the topic of differentiability, 5 out of 17 students showed that they were able to identify that a derivative does not exist in $f(x)=\sqrt[3]{x}$, in $x=0$ because the tangent line at that point is vertical: "At the points where the tangent line is vertical so the slope is undefined" (S4, E3). Another five students identified the situation correctly but had some conceptual errors when explaining it. In another case, 16 of 17 participants correctly explained that a reason for the function not being differentiable was the discontinuity, as explained by S10, "at points where the derivative is not continuous, because if it is not continuous it is not derivable" ( $\mathrm{E}_{3}$ ), or in other words, when "the lateral limits do not coincide" (S2, E3). These examples suggest that the students can express, in NL, the cases where a function is not differentiable. Later, we 
will see that they had some misconceptions regarding the same topic when using SL.

In addition, 9 out of 17 students were able to recognize, in NL and PL, how the derivative affects the shape of a graph. They correctly interpreted six or more of the features given in SL, including the $\lim _{x \rightarrow+\infty} f(x)$ and the intervals of monotony and concavity.

On the other hand, students were also successful at interpreting a statement of the optimization problem. They were able to recognize the variables and formulas as well as understanding the aim of the exercise. Fourteen out of seventeen students identified the area as the function to be minimized (see Table $3 \mathrm{C}$ ) and the volume as the auxiliary equation used to clear a variable and replace it in the original equation so that it is stated in terms of a single variable, as shown in Table $5 \mathrm{~A}$.

Finally, the students showed the ability to identify and explain errors in the solution of a derivative that involved the composition of two functions, one exponential and the other quadratic, through a combination of NL and SL. One of the errors was related to the performance of the chain rule. For that, students wrote “ $h^{\prime}(x) \neq g^{\prime}(f(x))$ " (S4, E17) or "Daniel forgot to multiply by $f^{\prime}(x)$ " (S14, E17). Other students (5 out of 17) attributed the error to how the composition of functions had been performed, remarking that first one must compose and then derive. In this way, they showed they were aware of the order of the composition despite it not being the source of the mistake. The other error was about the power rule, and it was also explained in both NL and SL. Answers like "the same base is left, and because it is multiplication, the exponents are added" (S6, E17) or "Josué's error is found in that $\left(e^{x}\right)^{2}$ is not $e^{x^{2}}$, but $e^{2 x}$ " $(\mathrm{S} 10, \mathrm{E} 17)$ are examples of the ways students explained the error, showing that they recognized the mistake and also knew the way to solve it.

\section{Misconceptions about mathematical concepts}

Analyzing the students' answers, we found misconceptions related to the use of symbols, conceptual understanding, and procedure. Regarding the use of symbols, the students' solutions showed a lack of rigor when writing mathematical symbols, for example, omitting " $f(x)$ " before the formula of a function or when writing a limit. The lack of rigor could also be found in the items left out of the optimization problem. The students did not consider the domain of the optimization function as necessary and omitted the prove that the point found was effectively a minimum point, as established by the problem. Another aspect left aside by 10 of 17 students was to determine both dimensions (height and radius) as requested in the statement; they 
only found the value of one variable. This demonstrates that the students did not read carefully or were only solving the problem mechanically.

More profound misconceptions related to the understanding of functions, algebra, derivatives, and continuity are also evident. For instance, in Example A in Table 8, there is an algebraic mistake: Because the second fraction is not defined, the denominator will be zero. The example in Table $8 \mathrm{~B}$ shows a mistake related to the definition of a function: The expressions $x=x^{2}$ and $x=-x^{2}+8$ are equations and do not define an association rule of a function. Additionally, the choice of the point $x=x_{0}$ does not indicate a specific value, so it could be assumed that the discontinuity would be fulfilled in any value that is assigned to $x_{0}$. However, for $x=2$ and $x=-2$, the given piecewise function would be continuous, contradicting what they intended to exemplify. S16 and S2 both gave a function continuous in all its domain as an example of a discontinuous function in Figure 4C. Other misinterpretations were related to considering the possibility of a function with vertical segments, writing "vertical function" ( $\left.\mathrm{S}_{5}, \mathrm{E}_{3}\right)$, or "the function will be a vertical line" (S17, E3).

Additionally, there were errors such as the direct association of derivatives with the tangent line, where the students use phrases like "the derivative was vertical" (S9) when actually the line was the one that was vertical at the point $x=0$, not the derivative.

Table 8. Students' mistakes in SL

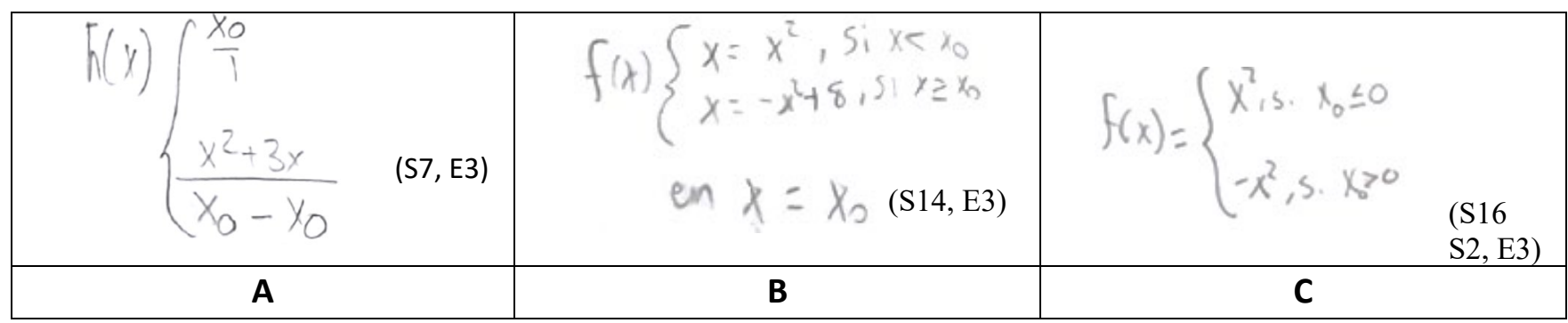

On the topic of differentiable functions, there were students who used the contrapositive of the rule "if a function is differentiable, then it is continuous" correctly, using NL in Exercise 3. However, when using or interpreting SL in Exercise 14, they made the false assumption that if the function is continuous, then it is differentiable. They also wrongly assumed that a continuous function does not have peaks, which could be influenced by the previous idea related to differentiability.

There were also misconceptions associated with the false assumption that all the points where the derivative is zero are maximum or minimal points before verifying 
the change in monotony. For instance, in E14 S16 wrote, "all the numbers less than 3 are minimums because the derivative is zero," and in this case, the interval ] $-\infty,-3$ [ corresponds to a constant segment. It is interesting how the student could decide that those points were minimums and not maximums when actually the function was constant. This constant section of the graph was also the most challenging feature for the students to draw. Six out of seventeen were not able to represent it correctly, drawing the segment as growing $\left(\mathrm{S}_{14}, \mathrm{E} 14\right)$ or ending the sketch in $x=-3$. On the other hand, plotting the concavity changes in the cases where there were no changes of monotony, as, in point $x=5$ shown in Table $9 \mathrm{~B}$, was also difficult for the participants.

Table 9. Students' difficulties in sketching the function (A: S14, B: S10)

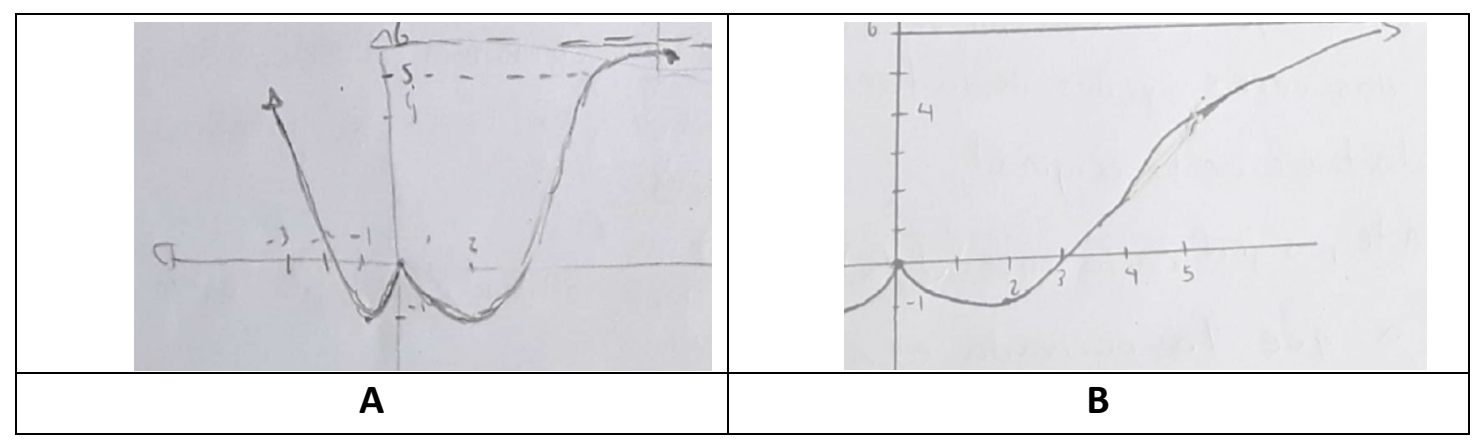

These examples show that students were not conscious of the consequences of misusing SL, that they had trouble using it for representing functions with specific characteristics, and had difficulty translating this language into NL. Also, they did not differentiate between mathematical objects, such as between a function correspondence rule and an equation or the derivative and the tangent line. They did not consider the basic rules for defining a fraction or connect the expressions in SL to an accurate graphical representation.

\section{Discussion}

The first university courses in mathematics, such as calculus, represent one of the most significant challenges for students. Learning at the university level requires the students to have conceptual understanding, skills to perform algebraic procedures, the ability to establish connections between concepts, and complex mathematical thinking. Previous studies suggest that representing mathematical concepts in 
different modes is essential in the meaning-making process (Schleppegrell, 2010). A concept such as the derivative, which can be defined from its analytical form as a limit, geometrically as the slope of the tangent line to a curve, or in physics as the rate of change at which a particle moves (Kaplan et al., 2015), must be studied using different representations.

The analysis of the languaging exercises answers presented in this paper made it possible to observe that the use of NL, PL, and SL favored the practice of four of the skills defined by Kilpatrick et al. (2001) as needed for learning mathematics. Conceptual understanding was the skill with the most features identified in the students' answers, namely, identifying, making, and verbalizing connections between concepts and understanding why a mathematical idea is important and why and where to use it. Procedural fluency was mostly seen supporting explanations given in NL or PL. Providing explanations and justifications in NL were the principal form in which adaptive reasoning was shown. The students needed to provide them in all the exercises despite the fact they were not used to doing so, which in fact relates to the strategic competence skill of solving novel situations.

The results also demonstrated students' thinking about the mathematical concepts involved and revealed some difficulties and misconceptions they made. Considering the strategies that they used to solve the tasks, the use of the variation tables stands out. They were used as an auxiliary resource in Exercise 14 as a summary table of the characteristics of the function for graphing and in Exercise 16 to perform the test of the first derivative. Another resource used by most of the students in Exercise 16 was the auxiliary equation. In this same exercise, most students were able to understand the problem and to identify the respective formulas of area and volume to differentiate. This result differs that of from Klymchuk et al. (2010), who categorized students' difficulties of in this type of problem as difficulties related to understanding the problem and difficulties related to the identification and usage of the formula. A possible explanation for this is that the students at the University of Costa Rica were already familiar with geometric optimization problems.

Regarding the difficulties and misconceptions observed, some were consistent with previous studies, such as an incorrect association of derivatives with the tangent line (Park, 2015), difficulties with the chain rule (Maharaj, 2013), and problems understanding the vertical tangent line and graphing an increasing upside-down function (Baker et al., 2000). Moreover, there were other problems identified, for instance, the lack of rigor with which students wrote mathematical expressions, which 
caused them to write mathematically ill-defined statements. Furthermore, phrases like "vertical function" indicated conceptual errors related to the definition function. On the other hand, the assertions that continuous functions have no peaks and that all points where the derivative becomes zero are minimal suggest that students were not aware of the conditions necessary to make such conclusions.

The experience of introducing languaging exercises in a calculus course for engineering students aimed to give them the opportunity to participate in the construction of their knowledge, for example, by asking for explanations using their own words. The exercises forced them to think instead of mechanically solving. Furthermore, the discussions and doubts that arose from the exercises provided valuable information about general misconceptions and the way students thought, for the teachers and the students themselves. These are not always possible to obtain when the class only focuses on developing procedural skills. The use of different languages was crucial to promoting the different competences, since each language plays a role in the conceptualization of problems (Schleppegrell, 2010) and the construction of meanings.

The results of this research highlight the importance of using different languages in the study of mathematical concepts. This is because it promotes essential competencies for learning mathematics and is a powerful instrument to observe students' thinking and identify misconceptions and gaps in their knowledge. Additionally, this study proved that it is possible to use this approach at the university level and in this way, address the problems of transition from school to university mathematics. Due to the small sample used in this study, it is not possible to generalize the results. However, they provide a valuable panorama of how this kind of exercise can be implemented and its utility in understanding and promoting students' comprehension of mathematical concepts. Further research could be conducted to investigate how or if the use of different languages affects students' performance in mathematics and study other possible ways of including this kind of exercise in evaluations.

\section{Acknowledgments}

We thank the University of Costa Rica for the study grant that supported this research, and all individuals that kindly agreed to collaborate. 


\section{References}

Alfaro, H. (2018). Appealing multimodal languages to access first year university students' understanding of mathematical concepts in Costa Rica [Master's thesis]. Tampere University. http://urn.fi/URN:NBN:fi:uta-201805041636

Artigue, M. (1995). La enseñanza de los principios del Cálculo: problemas epistemológicos, cognitivos y didácticos. In M. Artigue, R. Douady, L. Moreno, \& P. Gómez (Eds.), Ingeniería didáctica en educación matemática (pp. 97-140). Grupo Editorial Iberoamérica.

Baker, B., Cooley, L., \& Trigueros, M. (2000). A calculus graphing schema. Journal for Research in Mathematics Education, 31(5), 557-578. https://doi.org/10.2307/749887

Biza, I., Giraldo, V., Hochmuth, R., Khakbaz, A., \& Rasmussen, C. (2016). Research on teaching and learning mathematics at the tertiary level: State-of-the-art and looking ahead. Springer. https://doi.org/10.1007/978-3-319-41814-8

Blanco, P. (2019). La mayoría de estudiantes de primer ingreso reprueban examen de diagnóstico de matemática en la UCR.Universidad de Costa Rica.

https://www.ucr.ac.cr/noticias/2019/04/02/la-mayoria-de-estudiantes-de-primeringreso-reprueban-examen-de-diagnostico-de-matematica-en-la-ucr.html

Boesen, J., Helenius, O., Bergqvist, E., Bergqvist, T., Lithner, J., Palm, T., \& Palmberg, B. (2014). Developing mathematical competence: From the intended to the enacted curriculum. Journal of Mathematical Behavior, 33(1), 72-87.

htps://doi.org/10.1016/j.jmathb.2013.10.001

Engelbrecht, J., \& Harding, A. (2015). Interventions to Improve teaching and learning mathematics in first year courses. International Journal of Mathematical Education in Science and Technology, 46(7), 1046-1060.

https://doi.org/10.1080/0020739X.2015.1070441

Er, S. N. (2018). Mathematics readiness of first-year college students and missing necessary skills: perspectives of mathematics faculty. Journal of Further and Higher Education, 42(7), 937952. https://doi.org/10.1080/0309877X.2017.1332354

Fox, G., Campbell, S., Grinshpan, A., Xu, X., Holcomb, J., Bnteau, C., Lewis, J. \& Ramachandran, K. (2017). Implementing projects in calculus on a large scale at the University of South Florida. Journal of STEM Education, 18(3). https://www.learntechlib.org/p/180987

Goodchild, S., \& Rønning, F. (2014). Teaching mathematics at higher education. In H. Silfverberg, T. Kärki, \& M. S. Hannula (Eds.), Proceedings of NORMA14 (pp. 396-400). Finnish Research Association for Subject Didactics.

Gruenwald, N., Klymchuk, S., \& Jovanoski, Z. (2004). Reducing the gap between the school and university mathematics: University lecturers' perspective. The New Zealand Mathematics Magazine, 41(3), 12-24. http://hdl.handle.net/10292/8391

Hsieh, H.-F., \& Shannon, S. E. (2005). Three approaches to qualitative content analysis. Qualitative Health Research, 15(9), 1277-1288.

https://doi.org/10.1177/1049732305276687

Hong, Y. Y., Kerr, S., Klymchuk, S., McHardy, J., Murphy, P., Spencer, S., Thomas, M., \& Watson, P. (2009). A comparison of teacher and lecturer perspectives on the transition from secondary to tertiary mathematics education. International Journal of Mathematical Education in Science and Technology, 4O(7), 877-889.

https://doi.org/10.1080/00207390903223754

Hoyles, C., Newman, K., \& Noss, R. (2001). Changing patterns of transition from school to university mathematics. International Journal of Mathematical Education in Science and Technology, 32(6), 829-845. https://doi.org/10.1080/00207390110067635 
Joutsenlahti, J., Ali-Löytty, S., \& Pohjolainen, S. (2016). Developing learning and teaching in engineering mathematics with and without technology. In Proceedings of the 44th SEFI Annual Conference.

Joutsenlahti, J., \& Kulju, P. (2017). Multimodal languaging as a pedagogical model-A case study of the concept of division in school mathematics. Education Sciences, 7(1), 9. https://doi.org/10.3390/educsci7010009

Kaplan, A., Ozturk, M., \& Ocal, M. (2015). Relieving of misconceptions of derivative concept with derive. International Journal of Research in Education and Science, 1(1), 64-74. https://doi.org/10.46328/ijres.v1i1.18

Kempen, L., \& Biehler, R. (2014). The quality of argumentations of first-year pre-service teachers. In P. Liljedahl, C. Nicol, S. Oesterle, \& D. Allan (Eds.), Proceedings of the joint meeting of $P M E 38$ and $P M E-N A 36.3$, (pp. 425-432). PME.

Kilpatrick, J., Swafford, J., \& Findell, B. (2001). Adding it up: Helping children learn mathematics. National Academy Press.

Kline, S. L., \& Ishii, D. K. (2008). Procedural explanations in mathematics writing: a framework for understanding college students' effective communication practices. Written Communication, 25(4), 441-461. https://doi.org/10.1177/0741088308322343

Klymchuk, S., Zverkova, T., Gruenwald, N., \& Sauerbier, G. (2010). University students' difficulties in solving application problems in calculus: student perspectives. Mathematics Education Research Journal, 22(2), 81-91. https://doi.org/10.1007/BF03217567

Luk, H. S. (2005). The gap between secondary school and university mathematics. International Journal of Mathematical Education in Science and Technology, 36(2-3), 161-174. https://doi.org/10.1080/o0207390412331316988

Maharaj, A. (2013). An APOS analysis of natural science students' understanding of derivatives. South African Journal of Education, 33(1), 1-19. https://doi.org/10.15700/saje.v33n1a458

Morgan, C. (2002). The place of pupil writing in learning, teaching and assessing mathematics. In P. Gates, Issues in mathematics teaching (pp. 232-244). Routledge.

Mustoe, L., \& Lawson, D. (2002). Mathematics for the European engineer. A Curriculum for the twenty-first century. SEFI.

Nardi, E. (1996). The novice mathematician's encounter with mathematical abstraction: tensions in concept-image construction and formalization [Ph.D. thesis, University of Oxford].

O'Halloran, K. L. (2015). The language of learning mathematics: A multimodal perspective. The Journal of Mathematical Behavior, 40, 63-74. https://doi.org/10.1016/j.jmathb.2014.09.002

Park, J. (2015). Is the derivative a function? If so, how do we teach it? Educational Studies in Mathematics, 89(2), 233-250. https://doi.org/10.1007/s10649-015-9601-7

Prediger, S., \& Wessel, L. (2013). Fostering German-language learners' constructions of meanings for fractions-Design and effects of a language-and mathematics-integrated intervention. Mathematics Education Research Journal, 25(3), 435-456. https://doi.org/10.1007/s13394-013-0079-2

Rundgrén, A.; Joutsenlahti, J., \& Mäkinen, J. (2016) Is languaging experienced to improve understanding of structural mechanics? In Proceedings of the 44th SEFI Annual Conference (1215).

Schleppegrell, M. J. (2010). Language in mathematics teaching and learning: A research review. In J. N. Moschkovich (Ed.), Language and mathematics education: Multiple perspectives and directions for research (pp. 73-112). Information Age Pub.

Silius, K., Pohjolainen, S., Kangas, J., Miilumäki, T., \& Joutsenlahti, J. (2011). What can be done to bridge the competency gap between upper-secondary school and university mathematics? 
In 2011 IEEE Global Engineering Education Conference EDUCON (pp. 428-436). IEEE. https://doi.org/10.1109/EDUCON.2011.5773172

Universidad de Costa Rica, (2019) MA1001: Cálculo 1[Course syllabus]. www.emate.ucr.ac.cr

Varsavsky, C. (2010). Chances of success in and engagement with mathematics for students who enter university with a weak mathematics background. International Journal of Mathematical Education in Science and Technology, 41(8), 1037-1049. https://doi.org/10.1080/0020739X.2010.493238

Winsløw, C., Gueudet, G., Hochmuth, R., \& Nardi, E. (2018). Research on university mathematics education. In T.Dreyfus, M. Artigue, D. Potari, S. Prediger, \& K. Ruthven (Eds.), Developing research in mathematics education (pp. 82-96). Routledge. 